www.nature.com/pj

\title{
Enhancement of dye dispersibility in silica hybrids through local heating induced by the Imidazolium group under microwave irradiation
}

\author{
Yuichi Kajiwara $^{1,2}$, Kazuo Tanaka ${ }^{1}$ and Yoshiki Chujo ${ }^{1}$ \\ We prepared imidazolium-containing silica hybrid films by sol-gel reactions of 1-(trimethoxysilylpropyl)-3-methylimidazolium \\ chloride under microwave irradiation. Furthermore, we incorporated hydrophobic dyes such as pyrene and 1-pyrenecarboxaldehyde \\ into the silica hybrids, and we investigated the dispersion behaviors of these dyes in the matrices. The local heating of the \\ imidazolium groups under microwave irradiation was suggested to contribute to the enhancement of reaction rates in the sol-gel \\ process. Finally, we achieved the incorporation of higher dye concentrations in the silica hybrids compared with those achieved \\ with conventional heating.
}

Polymer Journal (2014) 46, 195-199; doi:10.1038/pj.2013.81; published online 25 September 2013

Keywords: hybrid; microwave; imidazolium; pyrene; sol-gel

\section{INTRODUCTION}

Dye-doped silica or glass materials and organic-inorganic hybrids have attracted significant attention in the fields of light-emitting diodes (LEDs), ${ }^{1,2}$ photochromic materials, ${ }^{3}$ optical sensors, ${ }^{4}$ biomaterials ${ }^{5-9}$ and solid-state dye laser oscillators. ${ }^{10}$ If organic dyes can be dispersed homogeneously and embedded in the matrices, then the luminescent properties of the dyes should be highly preserved. In particular, because the matrices restrict the molecular motion of the dyes and restrict the access of water and oxygen active species, the photostability of the dyes can be significantly enhanced. ${ }^{11-13}$ Interactions between the guest molecules and matrices have been found to have an important role in the immobilization of the dyes in the matrices and in the improvement of the photostability of the dyes. ${ }^{11-13}$ However, more effective approaches are still needed for immobilization of dye molecules because critical molecular motions of the dyes in the matrices could exist and cause dye degradation. ${ }^{11,12,14}$

Ionic liquids, which are air-stable molten salts and are in the liquid state below $100^{\circ} \mathrm{C}$, have received much attention in the field of chemistry as a 'green' recyclable alternative to traditional organic solvents. Various combinations and modifications of cations and anions allow the properties of ionic liquids to be tuned. Recently, microwave-assisted organic, inorganic and polymer syntheses with ionic liquids have been explored. ${ }^{15}$ Ionic liquids can absorb microwaves effectively because of their high polarity, and the ionic conduction induced by microwave irradiation can generate extremely large amounts of heat. Therefore, the combination of ionic liquids and microwave irradiation provides significant advantages such as the acceleration of reaction rates.
Often, by increasing the temperatures in a sol-gel reaction, the reaction time can be decreased. However, porous products are often obtained because of the rapid evaporation of the solvent. We expect that the incorporation of ionic compounds into the preparation of silica gels allows for the increase of localized heating under microwave irradiation and results in the rapid and homogeneous formation of silica materials. Here we prepared an imidazolium-containing alkoxysilane, 1-(trimethoxysilylpropyl)-3-methylimidazolium chloride (1, shown in Scheme 1), and the sol-gel reaction of 1 was performed under microwave irradiation to prepare imidazolium-containing silica hybrid films. Furthermore, we investigated the dispersion behaviors of the dyes in the imidazolium-containing hybrid matrices with pyrene and 1-pyrenecarboxaldehyde. The local heating caused by the imidazolium ions under microwave irradiation was found to allow the rapid formation of silica gel containing the alkoxysilane and to allow increases in the dye content without the loss of the optical properties in the silica matrices.

\section{EXPERIMENTAL PROCEDURE}

Materials

All reagents were purchased from commercial sources and were used as received without further purification.

\section{Measurements}

The ${ }^{1} \mathrm{H}(400 \mathrm{MHz})$ NMR spectra were recorded on a JEOL JNM-EX400 spectrometer (Jeol, Tokyo, Japan), and tetramethylsilane (TMS) was used as an internal standard in $\mathrm{CDCl}_{3}$. Scanning electron microscopy (SEM) measurements were conducted with a JEOL JSM-5600 system (Jeol). The luminescent spectra of the obtained hybrids were measured with a HORIBA JOBIN YVON FluoroMax-4

${ }^{1}$ Department of Polymer Chemistry, Graduate School of Engineering, Kyoto University, Kyoto, Japan and ${ }^{2}$ Matsumoto Yushi-Seiyaku Co., Ltd., Osaka, Japan Correspondence: Professor Y Chujo, Department of Polymer Chemistry, Graduate School of Engineering, Kyoto University, Katsura, Nishikyo-ku, Kyoto 615-8510, Japan. E-mail: chujo@chujo.synchem.kyoto-u.ac.jp

Received 27 June 2013; revised 5 August 2013; accepted 6 August 2013; published online 25 September 2013 


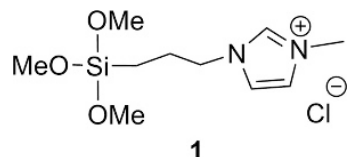

Scheme 1 Chemical structure of 1-(trimethoxysilylpropyl)-3-methylimidazolium chloride 1 .

fluorescence spectrometer (Horiba, Kyoto, Japan). Thermogravimetric analysis (TGA) was performed on a SEIKO TG/DTA 6200 (SEIKO, Tokyo, Japan) at a heating rate of $10^{\circ} \mathrm{Cmin}^{-1}$ in air. Fourier transform-infrared (FT-IR) spectra were recorded on a Perkin-Elmer 1600 infrared spectrometer (Perkin-Elmer, Waltham, MA, USA). Pyrene was dissolved in methanol and was cast on a glass plate to measure the optical properties of pyrene in the solid state.

\section{Synthesis of 1-(Trimethoxysilylpropyl)-3-methylimidazolium}

Chloride (1)

A mixture of 1-methylimidazole $(11.3 \mathrm{~g}, 0.137 \mathrm{~mol})$ and 3-chloropropyltrimethoxysilane $(27.3 \mathrm{~g}, 0.137 \mathrm{~mol})$ was stirred at $95^{\circ} \mathrm{C}$ for $24 \mathrm{~h}$ under nitrogen in a round-bottomed flask equipped with a reflux condenser. ${ }^{16}$ The mixture was washed with $\mathrm{Et}_{2} \mathrm{O}(40 \mathrm{ml} \times 5)$ and was dried at $90^{\circ} \mathrm{C}$ under vacuum. Yield: $96 \%$.

${ }^{1} \mathrm{H}$ NMR $\left(\mathrm{CDCl}_{3}, 400 \mathrm{MHz}\right): \delta=10.58(\mathrm{~s}, 1 \mathrm{H}, \mathrm{Ar}-\mathrm{H}), 7.65(\mathrm{t}, 1 \mathrm{H}, J=1.5$ $\mathrm{Hz}, \mathrm{Ar}-H), 7.43(\mathrm{t}, 1 \mathrm{H}, J=1.5 \mathrm{~Hz}, \mathrm{Ar}-H), 4.34\left(\mathrm{t}, 2 \mathrm{H}, J=7.3 \mathrm{~Hz}, \mathrm{Ar}-\mathrm{CH}_{2}-\right)$, $4.14\left(\mathrm{~s}, 3 \mathrm{H}, \mathrm{N}-\mathrm{CH}_{3}\right), 3.57$ (s, 9H, $-\mathrm{OCH}_{3}$ ), 2.02 (quint, $2 \mathrm{H}, J=7.3,8.1 \mathrm{~Hz}$, $\left.-\mathrm{CH}_{2} \mathrm{CH}_{2} \mathrm{CH}_{2}-\right), 0.64\left(\mathrm{t}, 2 \mathrm{H}, J=8.1 \mathrm{~Hz}, \mathrm{Si}-\mathrm{CH}_{2}-\right)$ p.p.m. ${ }^{13} \mathrm{C}$ NMR $\left(\mathrm{CDCl}_{3}\right.$, $100 \mathrm{MHz}): \delta=137.3,123.6,121.6,51.3,50.3,36.1,23.8,5.6$ p.p.m.

Preparation of imidazolium-containing silica matrices doped with pyrene and 1-pyrenecarboxaldehyde

The typical preparation procedure is shown here: 1-(Trimethoxysilylpropyl)-3methylimidazolium chloride $(1,0.40 \mathrm{~g})$ and methyltrimethoxysilane (MeTMOS, $0.60 \mathrm{~g})$ were dissolved in methanol $(10 \mathrm{ml})$, and $0.1 \mathrm{~N}$ aqueous hydrochloric acid $(1.0 \mathrm{ml})$ was added. MeTMOS was used to improve the formability of the films of the silica matrices. After stirring for $1 \mathrm{~h}, 2.0 \mathrm{ml}$ of a $20 \mathrm{~mm}$ solution of pyrene in methanol was added to the reaction solution. The resulting solution was poured into a polypropylene vessel and was heated in a microwave apparatus (Milestone General MicroSYNTH). The microwave irradiation conditions were $400 \mathrm{~W}$ for $10 \mathrm{~min}$, followed by $800 \mathrm{~W}$ for $20 \mathrm{~min}$. For conventional heating, the solution was heated in an oven at $60^{\circ} \mathrm{C}$ for $24 \mathrm{~h}$. The internal reaction temperature of the reaction solution under microwave irradiation was monitored with an optical fiber temperature sensor. When 1-pyrenecarboxaldehyde was used instead of pyrene, $2.0 \mathrm{ml}$ of $10 \mathrm{~mm}$ 1-pyrenecarboxaldehyde in methanol was added.

\section{RESULTS AND DISCUSSION}

The imidazolium-containing hybrids were prepared by the sol-gel reaction of 1-(trimethoxysilylpropyl)-3-methylimidazolium chloride (1) and methyltrimethoxysilane (MeTMOS) under microwave irradiation and conventional heating. Table 1 summarizes the results from both preparation methods for the films. We used MeTMOS to improve the formability of the films of the silica matrices. In both methods, transparent films were obtained when the weight ratios of 1 to MeTMOS were $1 / 4$ (run 2) and 2/3 (run 3 ). When only 1 was used (Table 1, run 6), sponge-like silica gels were obtained under microwave irradiation. In contrast, the materials prepared under conventional heating were viscous sols. It has been suggested that Species 1 absorbs microwaves efficiently, and the sol-gel reaction of 1 proceeded rapidly. When the sol-gel reaction of MeTMOS occurred in the presence of 1-butyl-3-methylimidazolium chloride (molar ratio of 1-butyl-3-methylimidazolium chloride to MeTMOS was 2/3), a transparent film was not obtained, and a viscous sol was formed. This result indicates that the covalent bond between the imidazolium group and the trimethoxysilyl group has an important role in the formation of homogeneous films.
Table 1 Preparation of imidazolium-containing hybrids

\begin{tabular}{|c|c|c|c|c|}
\hline \multirow[b]{2}{*}{ Run } & \multirow[b]{2}{*}{1 (g) } & \multirow[b]{2}{*}{ MeTMOS (g) } & \multicolumn{2}{|c|}{ Appearance } \\
\hline & & & Microwave ${ }^{a}$ & Conventionalp \\
\hline 1 & 0 & 1.0 & Turbid film & Turbid film \\
\hline 2 & 0.20 & 0.80 & Transparent film & Transparent film \\
\hline 3 & 0.40 & 0.60 & Transparent film & Transparent film \\
\hline 4 & 0.60 & 0.40 & Viscous gel & Viscous gel \\
\hline 5 & 0.80 & 0.20 & Sponge-like solid & Sol \\
\hline 6 & 1.0 & 0 & Sponge-like solid & Sol \\
\hline
\end{tabular}

Solvent, methanol $10 \mathrm{ml}$; catalyst, $0.10 \mathrm{~N}$ hydrochloric acid aqueous solution $1.0 \mathrm{ml}$ a Microwave irradiation condition was $400 \mathrm{~W}$ for $10 \mathrm{~min}$ and $800 \mathrm{~W}$ for $20 \mathrm{~min}$.

bReaction was carried out in an oven at $60^{\circ} \mathrm{C}$ for $24 \mathrm{~h}$.

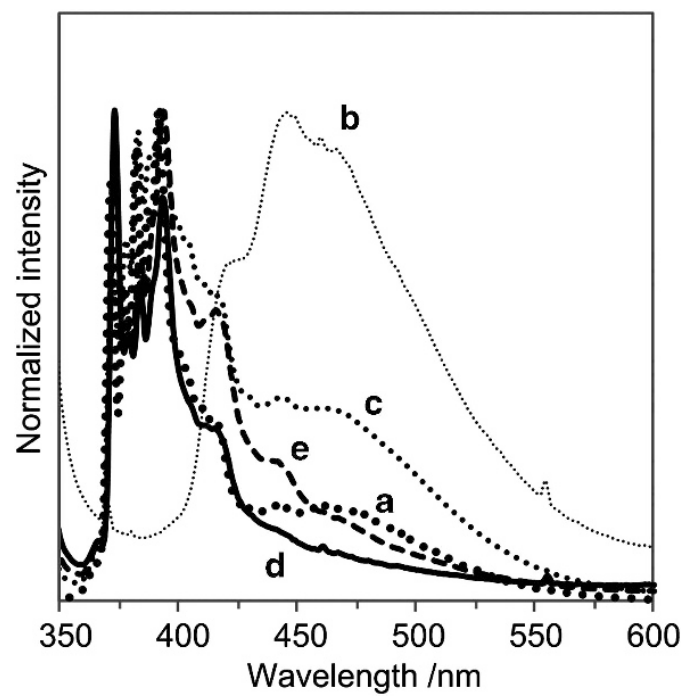

Figure 1 The photoluminescence spectra of pyrene in solution, in the solid state, and doped in imidazolium-containing hybrids. (a) $1.0 \times 10^{-3} \mathrm{M}$ solution in methanol, (b) in the solid state, (c) in a hybrid prepared under microwave irradiation (run 1), (d) in an imidazolium-containing hybrid prepared under microwave irradiation (run 3), (e) in an imidazoliumcontaining hybrid prepared under conventional heating (run 3). The amount of pyrene dopant in the hybrids was $40 \mu \mathrm{mol}$

Next, pyrene was incorporated into the imidazolium-containing hybrids prepared with both methods. Figure 1 shows the photoluminescence spectra of a $1.0 \times 10^{-3} \mathrm{M}$ solution of pyrene in methanol, pyrene in the solid state and the pyrene-doped hybrids. The amount of pyrene dopant in the hybrid matrix was $40 \mu \mathrm{mol}$. The pyrene exhibited excimer emission with a peak at $\sim 470 \mathrm{~nm}$ in methanol solution and showed an emission peak at $\sim 440 \mathrm{~nm}$ in the solid state. When the MeTMOS-based hybrids prepared under microwave irradiation (run 1) were doped with pyrene, a broad emission peak in the region from $420 \mathrm{~nm}$ to $500 \mathrm{~nm}$ was observed and could be attributed to the emission of pyrene aggregates. In contrast, the imidazolium-containing hybrid, which was obtained from $0.60 \mathrm{~g}$ of MeTMOS and $0.40 \mathrm{~g}$ of $\mathbf{1}$ (Table 1, run 3) and was prepared under microwave irradiation doped with pyrene, showed no emission derived from pyrene excimers or aggregates. These results suggest that the presence of imidazolium groups improved the dispersion of pyrene in the silica matrices. When the pyrene-doped hybrid was prepared under conventional heating, emission from pyrene aggregates was observed, and this emission indicates that pyrene molecules 
were dispersed more homogeneously in the hybrids prepared under microwave irradiation.

SEM images of the obtained hybrids doped with $40 \mu \mathrm{mol}$ of pyrene are shown in Figure 2. In the SEM image of the hybrid prepared under microwave irradiation (Figure $2 \mathrm{a}$ ), a few aggregates of pyrene were observed. In contrast, an inhomogeneous structure was observed in the film prepared under conventional heating. The aggregation of pyrene induced the critical phase separation in the film (Figure 2b).

The TGA profiles and FT-IR spectra of the obtained pyrene-doped hybrids prepared under microwave irradiation and conventional heating are shown in Figures 3 and 4, respectively. In Figure 3, the hybrids prepared under both methods showed almost the same behaviors upon pyrolysis. As shown in Figure 4, the FT-IR spectra of the hybrids prepared under both methods are similar. These results indicate that the heating methods should less significantly affect the degree of condensation of the alkoxysilanes and the structures of the obtained hybrids.

To explain the role of the imidazolium groups, the change in the internal temperatures during the microwave-assisted synthesis of the hybrids was monitored. The temperature profiles are shown in Figure 5. When only MeTMOS was used to enhance the dispersibility of the pyrene in the hybrid formation (Table 1, run 1), the temperature during the reaction was constant after it reached at $66^{\circ} \mathrm{C}$. In contrast, for run 3 , the reaction temperature reached $85^{\circ} \mathrm{C}$ after $180 \mathrm{~s}$. Subsequently, the temperature decreased gradually because
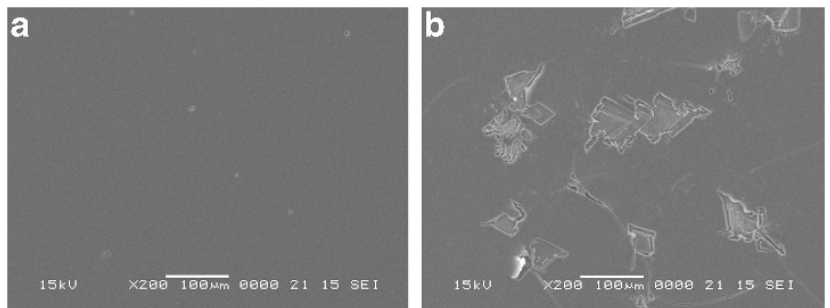

Figure 2 SEM images of pyrene-doped hybrids prepared under (a) microwave and (b) conventional heating. The amount of pyrene dopant in the hybrids was $40 \mu \mathrm{mol}$.

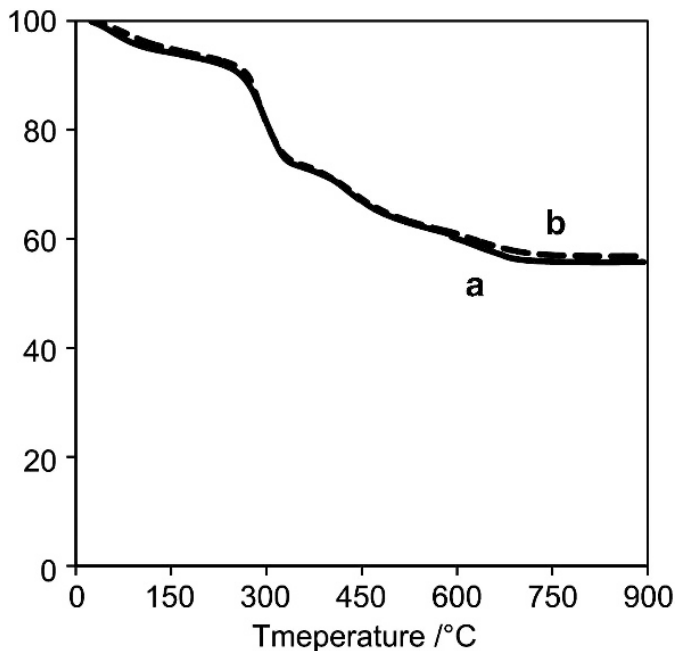

Figure 3 TGA profiles of pyrene-doped imidazolium-containing hybrids prepared under (a) microwave and (b) conventional heating. The amount of pyrene dopant in the hybrids was $40 \mu \mathrm{mol}$. of solvent evaporation. The imidazolium groups of $\mathbf{1}$ were found to absorb microwaves and convert the microwaves to heat.

The proposed mechanism for the enhancement of the dispersibility of pyrene in the hybrid under microwave irradiation is illustrated in Scheme 2. The solubility of the pyrene increased because of the local heating around the imidazolium groups induced by the microwave irradiation. Moreover, the sol-gel reaction of 1 and MeTMOS should have been enhanced by microwave heating. Consequently, the homogeneous dispersion of pyrene was improved in the hybrid matrices prepared under microwave irradiation relative to the dispersion in those matrices prepared under conventional heating.

Furthermore, the polarity of the environments surrounding the pyrene in the hybrid matrices was investigated. The relative intensity of emission bands $1\left(I_{1}\right)$ and $3\left(I_{3}\right)$ of pyrene $\left(I_{1} / I_{3}\right)$ is known to be correlated with the solvent polarity. ${ }^{17-19}$ The relative intensity increased as the environmental polarity increased around the pyrene molecule. When $40 \mu \mathrm{mol}$ of pyrene dopant was used, the relative intensities $I_{1} / I_{3}$ of the hybrids prepared under

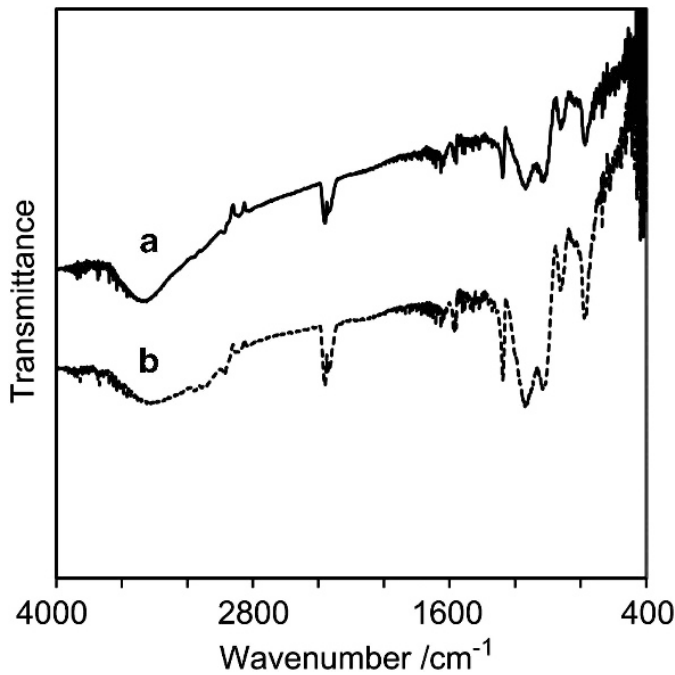

Figure 4 FT-IR spectra of pyrene-doped imidazolium-containing hybrids prepared under (a) microwave and (b) conventional heating. The amount of pyrene dopant in the hybrids was $40 \mu \mathrm{mol}$.

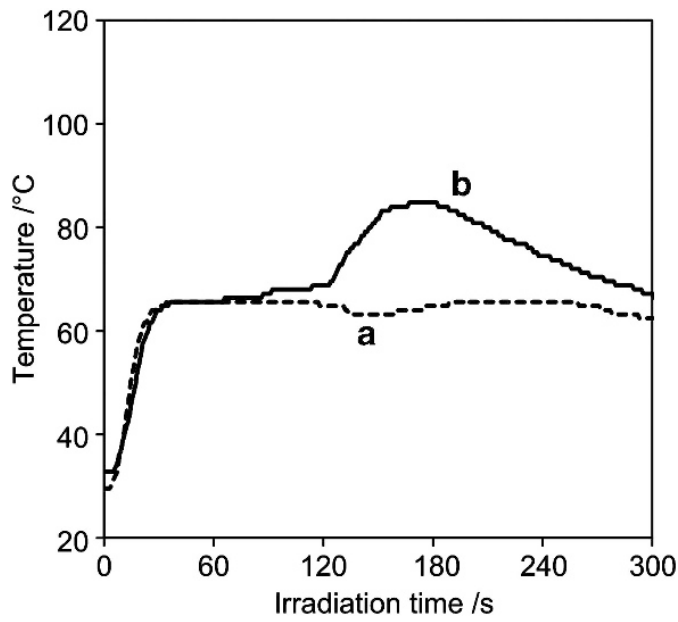

Figure 5 Temperature profiles for the reaction solution of (a) run 1 and (b) run 3 under microwave irradiation. 


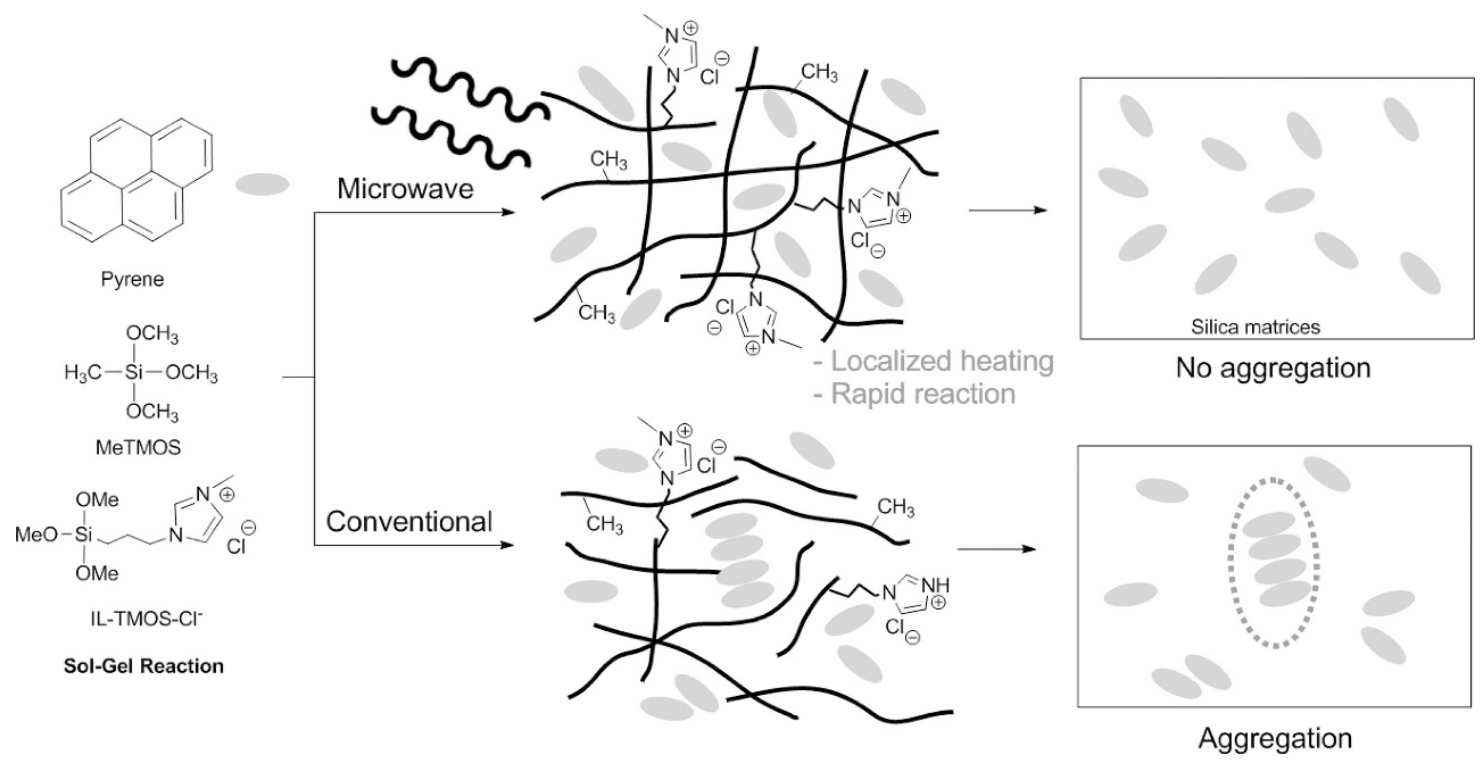

Scheme 2 Proposed mechanism for the homogeneous dispersion of pyrene in imidazolium-containing hybrids prepared under microwave irradiation. A full color version of this scheme is available at Polymer Journal online.

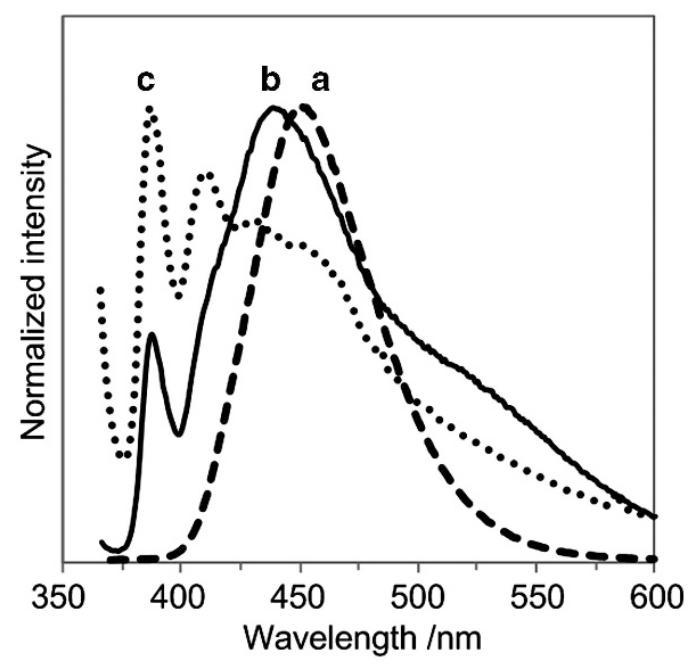

Figure $6 \mathrm{PL}$ spectra of 1-pyrenecarboxaldehyde in (a) methanol $(1.0 \times$ $\left.10^{-5} \mathrm{M}\right)$, (b) imidazolium-containing hybrid prepared under microwave irradiation and (c) imidazolium-containing hybrid prepared under conventional heating.

microwave irradiation and conventional heating were 1.55 and 1.30, respectively. This result indicates that the surroundings of the pyrene molecule are considerably polar. In addition, pyrene molecules in the hybrids prepared under microwave irradiation were located in more polar environments than the molecules prepared under conventional heating. For the MeTMOSbased hybrids, the relative intensities $I_{1} / I_{3}$ of the hybrids prepared under microwave irradiation and conventional heating were 0.88 and 0.70 . These results suggest that the hydrophobic pyrene molecules could be dispersed even in the hydrophilic environment of the hybrid matrices prepared under microwave irradiation.

1-Pyrenecarboxaldehyde is widely used as a probe for solvent polarity in various isotropic and complex solubilizing media. The fluorescence maxima of 1-pyrenecarboxaldehyde are known to redshift as the dielectric constant of the surrounding milieu increases. ${ }^{20}$ We incorporated 1-pyrenecarboxaldehyde into the hybrids in the same manner as pyrene was incorporated. Figure 6 shows the PL spectra of 1-pyrenecarboxaldehyde in solution and in the hybrids prepared under microwave irradiation and conventional heating. The peak of 1-pyrenecarboxaldehyde in methanol was at $451 \mathrm{~nm}$. In contrast, the peak of the imidazoliumcontaining hybrid prepared under microwave irradiation was at $438 \mathrm{~nm}$, which was a slight blueshift. The PL spectrum of 1pyrenecarboxaldehyde in the hybrid prepared under conventional heating was measured, and the observed spectrum was similar to that in cyclohexane. ${ }^{20}$ The peak of the emission band from 1pyrenecarboxaldehyde in the hybrid prepared under conventional heating was at $387 \mathrm{~nm}$. These results suggest that the polarity of the hybrid prepared under microwave irradiation was higher than that prepared under conventional heating, similar to pyrene. Isolation of the dyes might occur in the film prepared under microwave irradiation.

\section{CONCLUSIONS}

We demonstrated the microwave-assisted preparation of imidazolium-containing hybrids and effective incorporation of hydrophobic dyes, such as pyrene and 1-pyrenecarboxaldehyde, into the hybrid matrices. Compared with conventional heating, microwave irradiation allowed the incorporation of a higher concentration of hydrophobic dyes in the hybrid matrices. In addition, local heating of imidazolium groups under microwave irradiation and acceleration of the sol-gel reaction led to the incorporation of hydrophobic dyes in more polar environments. This method will be applicable to various types of hydrophobic molecules and will lead to the design of optical materials with excellent luminescent properties.

\section{ACKNOWLEDGEMENTS}

This work was partially supported by the Kansai Research Foundation for the promotion of technology. 
1 Dantas de Morais, T., Chaput, F., Lahlil, K. \& Boilot, J.-P. Hybrid organic-inorganic light-emitting diodes. Adv. Mater. 11, 107-112 (1999).

2 Dantas de Morais, T., Chaput, F., Boilot, J.-P., Lahlil, K., Darracq, B. \& Lévy, Y. Hole mobilities in sol-gel materials. Adv. Mater. Opt. Electron. 10, 69-79 (2000).

3 Biteau, J., Chaput, F., Yokoyama, Y. \& Boilot, J.-P. Photochromism of an indolylfulgide trapped in a hybrid sol-gel matrix. Chem. Lett. 27, 359-360 (1998).

4 Rottman, C., Grader, G., De Hazan, Y., Melchior, S. \& Avnir, D. Surfactant-induced modification of dopants reactivity in sol-gel matrixes. J. Am. Chem. Soc. 121, 8533-8543 (1999).

5 Tanaka, K., Jeon, J.-H., Inafuku, K. \& Chujo, Y. Enhancements of optical properties of dyes for bioprobes by freezing effect of molecular motion using POSS-core dendrimers. Bioorg. Med. Chem. 20, 915-919 (2012).

6 Tanaka, K., Murakami, M., Jeon, J.-H. \& Chujo, Y. Enhancement of affinity in molecular recognition via hydrogen bonds by POSS-core dendrimer and its application for selective complex formation between guanosine triphosphate and 1,8-naphthyridine derivatives. Org. Biomol. Chem. 10, 90-95 (2012).

7 Tanaka, K., Ohashi, W., Kitamura, N. \& Chujo, Y. Reductive glutathione-responsive molecular release using water-soluble POSS network polymers. Bull. Chem. Soc. Jpn 84, 612-616 (2011).

8 Tanaka, K., Kitamura, N. \& Chujo, Y. Bi-modal quantitative monitoring for enzymatic activity with simultaneous signal increases in ${ }^{19} \mathrm{~F}$ NMR and fluorescence using silica nanoparticle-based molecular probes. Bioconjugate Chem. 22, 1484-1490 (2011).

9 Tanaka, K., Inafuku, K., Naka, K. \& Chujo, Y. Enhancement of entrapping ability of dendrimers by a cubic silsesquioxane core. Org. Biomol. Chem. 6, 3899-3901 (2008).

10 García, O., Garrido, L., Sastre, R., Costela, A. \& García-Moreno, I. Synthetic strategies on hybrid materials improving properties for optoelectronic applications. Adv. Funct. Mater. 18, 2017-2025 (2008).
11 Gilliland, J. W., Yokoyama, K. \& Yip, W. T. Solvent effect on mobility and photostability of organic dyes embedded inside silica sol-gel thin films. Chem. Mater. 17, 6702-6712 (2005).

12 Lei, Q. \& Yip, W. T. Probing the effect of post-synthesis grafting on guest-host interactions in sol-gel silica with single-molecule mobility and photostability. J. Phys. Chem. C 113, 21130-21138 (2009).

13 Ye, F., Collinson, M. M. \& Higgins, D. A. What can be learned from single molecule spectroscopy? Applications to sol-gel-derived silica materials. Phys. Chem. Chem. Phys. 11, 66-82 (2009).

14 Hellriegel, C. Kirstein, J., Brauchle, C. Latour, V., Pigot, T., Lacombe, S., Brown, R., Guieu, V., Payrastre, C., Izquierdo, A. \& Mocho, P. Diffusion of single streptocyanine Molecules in the nanoporous network of sol-gel glasses. J. Phys. Chem. B 108, 14699-14709 (2004).

15 Martínez-Palou, R. Microwave-assisted synthesis using ionic liquids. Mol. Divers 14, 3-25 (2010).

16 Valkenberg, M. H., deCastro, C. \& Hölderich, W. F. Immobilisation of chloroaluminate ionic liquids on silica materials. Top. Catal 14, 139-144 (2001).

17 Nakajima, A. Variations in the vibrational structures of fluorescence spectra of naphthalene and pyrene in water and in aqueous surfactant solutions. Bull. Chem. Soc. Jpn 50, 2473-2474 (1977).

18 Kalyanasundaram, K. \& Thomas, J. K. Environmental effects on vibronic band intensities in pyrene monomer fluorescence and their application in studies of micellar systems. J. Am. Chem. Soc. 99, 2039-2044 (1977).

19 Dong, D. C. \& Winnik, M. A. The Py scale of solvent polarities. Can. J. Chem. 62 , 2560-2565 (1984).

20 Fretcher, K. A., Storey, I. A., Hendricks, A. E., Pandey, S. \& Pandey, S. Behavior of the solvatochromic probes Reichardt's dye, pyrene, dansylamide, Nile Red and 1 -pyrenecarbaldehyde within the room-temperature ionic liquid bmimPF 6 . Green Chem. 3, 210-215 (2001). 